\title{
Evaluation of Humidity Correction Methods for Vaisala RS92 Tropical Sounding Data
}

\author{
HuNGJUI Yu \\ Department of Atmospheric Sciences, National Taiwan University, Taipei, Taiwan \\ PAul E. Ciesielski \\ Department of Atmospheric Science, Colorado State University, Fort Collins, Colorado \\ JUNHONG WANG \\ Department of Atmospheric and Environmental Sciences, University at Albany, State \\ University of New York, Albany, New York \\ HuNG-CHI KuO \\ Department of Atmospheric Sciences, National Taiwan University, Taipei, Taiwan \\ HOLGER VÖMEL AND RUUD DIRKSEN \\ Meteorological Observatory Lindenberg, DWD, Germany
}

(Manuscript received 25 August 2014, in final form 29 December 2014)

\begin{abstract}
This study examines the DigiCORA and Global Climate Observing System Reference Upper-Air Network (GRUAN) humidity corrections of Vaisala RS92 radiosondes at three sites over the tropical Indian Ocean and surrounding areas during the Dynamics of the Madden-Julian Oscillation (DYNAMO) field campaign in 2011. The proprietary DigiCORA correction algorithm is built into the ground station software provided by Vaisala, whereas the GRUAN correction is an open source algorithm. Included in the GRUAN data product are uncertainty estimates for their corrections. This information is used to examine the statistical consistency of the various corrections.

In general, the algorithms produce a positive relative humidity $(\mathrm{RH})$ correction that increases with altitude related primarily to a solar radiation dry bias adjustment. For example, in daytime soundings the relative $\mathrm{RH}$ correction increases from a few percent for temperatures $>0{ }^{\circ} \mathrm{C}$ to $20 \%-40 \%$ between 100 and $200 \mathrm{hPa}$. Comparison of corrected RH vertical profiles show only small differences (on the order of a few percent or less at any given level) between the DigiCORA and GRUAN algorithms, such that these corrections are considered to be statistically consistent at most levels.

In evaluating corrected humidity data with independent estimates of total precipitable water (TPW), good agreement was found at all sites between corrected sounding and ground-based microwave radiometer (MWR) estimates of TPW with mean differences $\leq 0.9 \mathrm{~mm}$ ( or $<2 \%$ ), which is well within the uncertainty of these measurements. Overall, the correction algorithms examined herein perform well over a wide range of tropical moisture conditions.
\end{abstract}

Corresponding author address: Hung-Chi Kuo, Department of Atmospheric Sciences, National Taiwan University, No. 1, Sec. 4, Roosevelt Road, Taipei 10617, Taiwan.

E-mail: kuo@as.ntu.edu.tw

\section{Introduction}

Radiosonde data, with a long record of over 60 years and high vertical resolution $(5-10 \mathrm{~m})$, play an important role in helping us detect and quantify climate change 


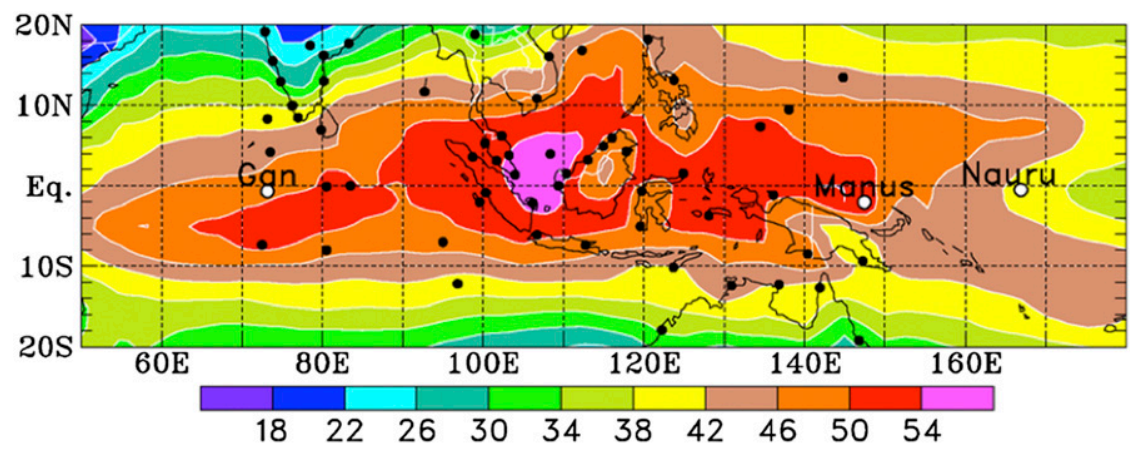

FIG. 1. Map showing east-most portion DYNAMO upper-air sounding network along with the averaged TPW (mm) for the period 1 Oct- 31 Dec 2011 from NCEP reanalysis. Black dots indicate the location of sounding sites with labeled white circles showing the location of sites used in this study.

and variability in the atmosphere (Thorne et al. 2011). Unfortunately, its usage has been limited by radiosonde sensor-dependent systematic biases, which can vary substantially over space and time and introduce nonclimatic changes or inhomogeneities in historical data records from radiosonde measurements (e.g., Dai et al. 2011). Therefore, the historic radiosonde record needs to be homogenized before it can be used to study climate trends. For the homogenization, it is essential to know when and where the changes were made and understand the error characteristics of old and new radiosonde types. This study focuses on the radiosonde humidity measurement, which is the least understood and most challenging to observe (Miloshevich et al. 2009; Nash et al. 2011).

Within the global radiosonde upper-air network, which includes over 800 sites and about 18 sonde types, the Vaisala RS92 is the most widely used radiosonde (at $>50 \%$ of the sites). Its humidity errors have been studied extensively, and various correction methods were developed to correct known biases (e.g., Vömel et al. 2007a,b; Yoneyama et al. 2008; Miloshevich et al. 2009; Wang et al. 2013). In response to these findings, Vaisala introduced a new algorithm to correct the solar radiation dry bias (SRDB) and time-lag error in RS92 humidity data during the eighth WMO Intercomparison of High Quality Radiosonde Systems, held in Yangjiang, China, in July 2010 (Nash et al. 2011). It was shown to greatly improve the RS92 humidity measurements, especially in the upper troposphere and during daytime (Nash et al. 2011). The new algorithm was implemented in the DigiCORA sounding software, version 3.64, in early 2011 (see the appendix for details). However, because of the proprietary nature of the DigiCORA algorithm and a lack of station metadata regarding if and when sites were upgraded to this new software, its impact on radiosonde climate records remains unknown, and moreover, it cannot be adapted and improved by users for their data (Wang et al. 2013). Thus, an important first step is a thorough evaluation of the data produced by this new algorithm.

To address the shortcomings of the global operational networks for climate studies and to ensure that future climate records are more useful than the records to date, the Global Climate Observing System (GCOS) program initiated a GCOS Reference Upper-Air Network (GRUAN) consisting of 18 sites worldwide (Seidel et al. 2009). Vaisala RS92s are launched regularly at 13 of the current GRUAN candidate stations. GRUAN developed algorithms to correct systematic errors in RS92 data and to derive an uncertainty estimate for each data point and each parameter (Immler and Sommer 2011; Dirksen et al. 2014). All current GRUAN algorithms are well documented in peer-reviewed journal articles and details are openly disclosed to the users. This provides us an opportunity to compare the GRUAN-corrected RS92 data with Vaisala DigiCORA-corrected ones.

The upper-air sounding network from the Dynamics of the Madden-Julian Oscillation (DYNAMO) field campaign (Fig. 1), centered over the Indian Ocean, collected over 13000 high-vertical-resolution $(5-10 \mathrm{~m})$ soundings primarily during its intensive observing period (IOP) from October to December 2011. These sounding observations are being used to study the Madden-Julian oscillation (MJO) initiation over the Indian Ocean, where its deep convective signal typically originates, and its subsequent evolution over the Maritime Continent and west Pacific warm pool region. Since one of the primary objectives of DYNAMO is to determine the mechanisms by which the troposphere is moistened in the MJO initiation stage (Yoneyama et al. 2013), a special effort was undertaken to create the "best possible" set of sounding humidity observations (Ciesielski et al. 2014). To assist in evaluating the quality of the DYNAMO observations, Vaisala RS92SGP (RS92) radiosonde data for three sites (Gan, Manus, 
and Nauru) were reprocessed using the GRUAN data processing. This dataset of high-quality radiosonde observations provides a unique opportunity to evaluate the GRUAN and DigiCORA humidity corrections in a tropical environment.

The purpose of this paper is to compare humidity correction methods for Vaisala RS92 tropical sounding data. Two DigiCORA algorithms will be examined here: DigiCORA 3.64, which was used at Gan and Manus, and DigiCORA 3.61 used at Nauru. This latter algorithm, which is still widely used, is supplemented with a SRDB correction (Wang et al. 2013) patterned after that used in the GRUAN software. This study will allow us to characterize the strengths and limitations of these three algorithms, as well as to extend their previous evaluations, which were limited to high- and midlatitude sites (Wang et al. 2013; Dirksen et al. 2014) with drier environments than the tropical sites examined here.

Section 2 describes the various data sources and correction methods used in this study. The relative humidity corrections and their uncertainty are examined in section 3 . In section 4, independent measures of cloudiness and column-integrated humidity are used to evaluate the corrections. A summary and concluding remarks are provided in section 5 .

\section{Data sources and correction methods}

\section{a. Large-scale context for sounding observations}

Upper-air sounding data from three DYNAMO sites (indicated with white circles in Fig. 1) are used in this study to evaluate the various corrections applied to radiosonde humidity data at these sites. These sites were chosen because 1) both DigiCORA and GRUAN corrections were applied to their sounding data and 2) being Department of Energy (DOE) Atmospheric Radiation Measurement (ARM) Program sites, they were equipped with collocated GPS and microwave radiometer (MWR) total-column precipitable water (TPW) observations to help validate RH corrections. Also shown in Fig. 1 is the horizontal distribution of mean TPW from 1 October to 31 December 2011, the period of available DigiCORAand GRUAN-corrected data used in this study. As seen here the meridional width of the equatorial moist tongue varies considerably over this domain being broadest over the longitudes of the Maritime Continent. Straddling this moisture maximum, the three sites span a broad range of moisture conditions ranging from a moisture-rich environment at Manus to more arid conditions at Nauru, which sits on the eastern edge of the west Pacific warm pool. The time-longitude plot of TPW for this period (Fig. 2) clearly shows the moisture signature associated

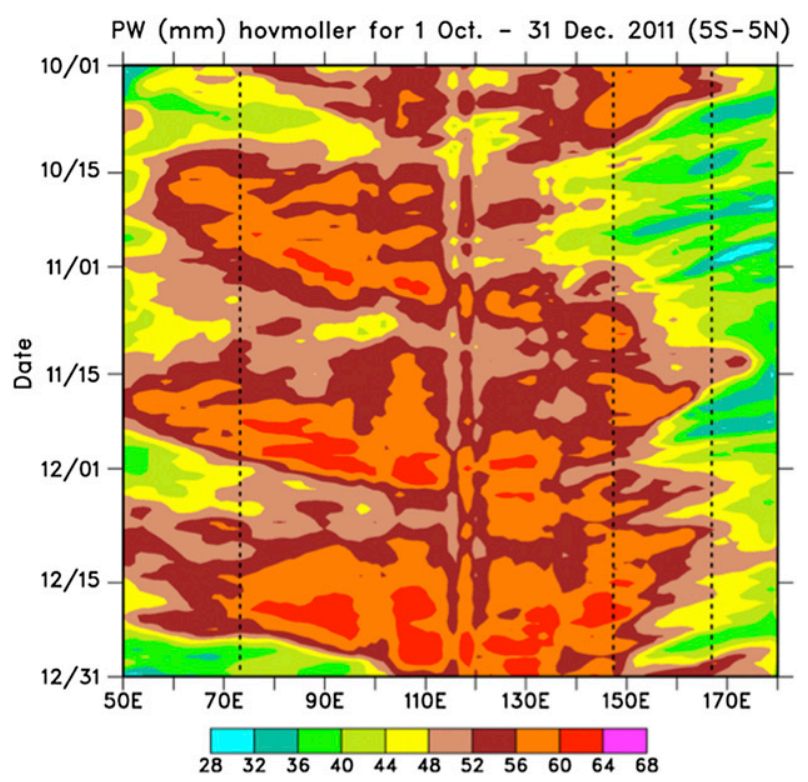

FIG. 2. Time-longitude plot of TPW $(\mathrm{mm})$ averaged from $5^{\circ} \mathrm{S}$ to $5^{\circ} \mathrm{N}$ for period 1 Oct-31 Dec 2011 based on ECMWF operational analysis. Vertical dashed lines indicate longitudinal positions of Gan, Manus, and Nauru (from left to right).

with three eastward-propagating intraseasonal signals in this region. With the passage of these oscillations, each site experienced large fluctuations in their moisture field with daily TPW values varying by $20-30 \mathrm{~mm}$ between periods of active and suppressed convection.

\section{b. Correction methods}

Each of the sounding sites considered here used Vaisala RS92-SGP radiosondes manufactured from 2009 to 2011. The uncorrected humidity data in this study are based on the 1-s-resolution raw data contained in the DigiCORA III database (DC3DB) files. Ground check corrections based on the Vaisala GC25 prelaunch recalibration of the humidity sensor have been eliminated from all sounding data. The GRUAN corrections are applied to the uncorrected humidity data as described in Dirksen et al. (2014). Two of the sites (Gan and Manus) used DigiCORA 3.64 (D3.64) ground station software. This software version, introduced by Vaisala in 2011, provides humidity corrections for the daytime soundings that include an SRDB correction and a time-lag correction for the slow response of the humidity sensor at cold temperatures (Miloshevich et al. 2009). At nighttime, only time-lag corrections are applied in the DigiCORA 3.64 software. Because of the proprietary nature of the DigiCORA software, information on the details of these corrections is not available.

The SRDB, being the largest of the corrections, was first quantified in a study by Vömel et al. (2007b), who found relative RH dry biases $\sim 9 \%$ near the surface 
TABLE 1. Summary of corrections applied within each algorithm as a function of day or night. Note that implementation of SRBC and time-lag correction between GRUAN and D3.64 are different. See text for additional details.

\begin{tabular}{|c|c|c|}
\hline \multirow[b]{2}{*}{ Algorithm } & \multicolumn{2}{|c|}{ Corrections Applied } \\
\hline & Day & Night \\
\hline GRUAN & $\begin{array}{l}\text { Calibration correction, } \\
\text { SRBC, time lag }\end{array}$ & $\begin{array}{l}\text { Calibration correction, } \\
\text { time lag }\end{array}$ \\
\hline D3.64 & SRBC, time lag & Time lag \\
\hline D3.61N & NRBC & None \\
\hline
\end{tabular}

increasing to $>50 \%$ near $100 \mathrm{hPa}$. Changes to the coating of the RS92 humidity sensor in 2006 and 2008 (Vaisala 2015) have reduced but not eliminated these biases. The Nauru site used DigiCORA 3.61 (D3.61) software, which does not have a built-in SRDB correction. For the Nauru humidity data, a recent correction scheme developed by Wang et al. (2013), referred to as the NCAR Radiation Bias Correction (NRBC), was applied. Hereafter, the D3.61-NRBC-corrected radiosondes shall be referred to as D3.61N. Designed to correct the SRDB and being a function of pressure, temperature, and solar elevation angle, this easy-to-use algorithm is based on the more complicated GRUAN correction. A complete description of the processing and quality control of the Vaisala sounding collected in DYNAMO is contained in Ciesielski et al. (2014).

As in the D3.64 software, the GRUAN algorithm also includes SRDB and time-lag corrections, although the exact nature and implementation of these corrections are likely different (Dirksen et al. 2014). In addition, the GRUAN algorithm includes a temperature-dependent calibration correction that is present at temperature $T<$ $0^{\circ} \mathrm{C}$ and peaks near $-50^{\circ} \mathrm{C}$ (Vömel et al. 2007a). Moreover, the version 2 GRUAN data products, in accordance with GRUAN philosophy (Immler et al. 2010), attempt traceability to SI units standards and contain vertical profiles of the corrected data, the corrections applied, and uncertainty estimates of both. Having both corrected data and the corrections allowed us to back out the uncorrected data to isolate the impact of the corrections. Corrections for all three algorithms used in this study are summarized in Table 1.

\section{c. Other data sources}

To evaluate radiosonde humidity corrections, independent estimates of TPW are valuable for determining sonde TPW biases. In this study, independent estimates of TPW came from two sources: ground-based MWR retrievals (Cady-Pereira et al. 2008) and ground-based global positioning system (GPS) estimates (Wang et al. 2007). The GPS TPW data at Gan, Manus, and Nauru were processed by UCAR using the network method (Ware et al. 2000). The reported accuracy of GPS TPW retrievals is $\sim 1-2 \mathrm{~mm}$ (Liou et al. 2001; Bock et al. 2007; Bock and Nuret 2009; Wang et al. 2007). Cadeddu et al. (2013) reported the uncertainty in MWR TPW retrievals to be $0.5 \mathrm{~mm}$ with a calibration independent of sonde data, making them an excellent source for identifying sonde biases. Because MWR observations are not reliable when liquid water is present on the radiometer window, rain-contaminated MWR estimates were not used in this study if their TPW value exceeded the sonde TPW by $1.5 \sigma$, where $\sigma$ is the sonde TPW standard deviation.

To facilitate comparisons with sonde TPW, the 30-min GPS estimates and the 1-min two-channel MWR channel radiometer data were averaged into 1-h bins centered on nominal sonde launch times. ${ }^{1}$ To account for differences in elevation between the radiosonde and GPS sites, the sonde TPW computation began at the height of the GPS receiver. For comparison of sonde corrections, high-resolution sonde data from both GRUAN and DigiCORA correction systems were considered, only if they (i) attained a height of $100 \mathrm{hPa}$ and (ii) had pressure, temperature, and RH (i.e., fields needed to compute TPW) available at all levels. Table 2 (rightmost column) shows the number of times when all three TPW data sources (radiosonde, GPS, and MWR) had cotemporaneous, reliable data for comparison purposes.

Fractional cloudiness is obtained from the Clouds and the Earth's Radiant Energy System (CERES) product at 3-hourly intervals on a $1^{\circ}$ grid (Wielicki et al. 1996). To estimate fractional cloudiness for the three sounding sites in question, this product was averaged in a circle with a $1^{\circ}$ radius centered on each site's location.

\section{Characterization of corrections and their uncertainty}

To characterize the corrections and to examine their differences, mean vertical RH profiles were constructed as shown in Figs. 3-5 for the three sites under consideration. Here the analyses have been separated into daytime and nighttime soundings to highlight the differences in corrections between these two periods. Included in these figures are the mean profiles and uncertainty estimates of the measurements provided by GRUAN (left panels), the relative correction ${ }^{2}$ (RC) derived by differencing the corrected and uncorrected data (RH_cor) and then dividing by the uncorrected $\mathrm{RH}$ value (middle

\footnotetext{
${ }^{1}$ The TPW comparisons were repeated with 2- and 3-h binned data with no substantial change in the results.

${ }^{2}$ The relative correction is a percentage difference of the measured uncorrected value-not an RH difference.
} 
TABLE 2. Pertinent information for upper-air sounding sites used in this study. See text for additional information regarding DigiCORA versions and definition of reliable soundings.

\begin{tabular}{lcccc}
\hline \hline \multicolumn{1}{c}{ Station } & $\begin{array}{c}\text { DigiCORA } \\
\text { software version }\end{array}$ & $\begin{array}{c}\text { Sounding temporal } \\
\text { resolution }\end{array}$ & $\begin{array}{c}\text { No. of reliable } \\
\text { soundings }\end{array}$ & $\begin{array}{c}\text { No. of reliable cotemporaneous } \\
\text { TPW observations }\end{array}$ \\
\hline Gan $(\mathrm{LT}=\mathrm{UTC}+5 \mathrm{~h})$ & 3.64 & $3 \mathrm{~h}$ & 634 & 458 \\
Manus $(\mathrm{LT}=\mathrm{UTC}+10 \mathrm{~h})$ & 3.64 & $3 \mathrm{~h}$ & 429 & 336 \\
Nauru $(\mathrm{LT}=\mathrm{UTC}+12 \mathrm{~h})$ & D3.61N & $12 \mathrm{~h}$ & 115 & 104 \\
\hline
\end{tabular}

panels), and the consistency between the corrections (right panels). The profiles of uncertainty range (shown as light blue lines in the leftmost panels of Figs. 3-5) were calculated by adding and subtracting the total uncertainty of the GRUAN measurements $\left(u_{1}\right)$ to the GRUANcorrected RH at each level and for each sounding.

The consistency test for RH_cor considered here follows the approach of Immler et al. (2010), in which the difference between two measurements $(m)$ and their combined uncertainty $(u)$ are used to define a consistency (or $k$ factor) as seen in the following equation:

$$
\left|m_{1}-m_{2}\right|<k \sqrt{u_{1}^{2}+u_{2}^{2}}
$$

where $k \leq 1$ indicates consistency, $1<k<2$ indicates agreement, $2<k<3$ indicates significant difference, and $k \geq 3$ indicates inconsistency. For this analysis, $m_{1}$ and $m_{2}$ are set to be the GRUAN- and DigiCORAcorrected RH, respectively, at each level. Since DigiCORA does not provide any uncertainty estimates, following the recommendation of Immler et al. (2010), the DigiCORA RH measurement uncertainty $\left(u_{2}\right)$ is assumed to be zero, which lowers the range of the uncertainties and hence makes the test statistically more conservative in that it results in the largest possible $k$ factor (Immler et al. 2010). With these input and assumptions, the consistency $k$ is then calculated using the above-mentioned equation. The standard deviation of $k$ (shown with light blues lines in the rightmost panels of Figs. 3-5) expresses its spread for the dataset of $\mathrm{RH}$ corrections considered (i.e., $68 \%$ of the $k$ factors computed for this dataset fall within these bounds assuming a normal distribution).

Examining the mean RH profiles for Gan (Fig. 3), we see that the D3.64-corrected daytime and nighttime soundings lie within the uncertainty of the GRUAN measurements and as expected $k<1$ at nearly all levels. Thus, the GRUAN- and DigiCORA-corrected RHs are statistically consistent. For the daytime Gan soundings, the RC (middle-top panel) shows that both algorithms result in RCs that increase with height to a maximum of $\sim 20 \%$ for GRUAN and $\sim 30 \%$ for D3.64 at upper levels. Though the precise reasons for the larger daytime D3.64 corrections cannot be specified due to the proprietary nature of its algorithm, most likely it is related to the D3.64 implementation of the SRDB correction. The nighttime corrections are considerably smaller. For example, the D3.64 algorithm produces only a slight (few percent) mean negative $\mathrm{RC}$ above $150 \mathrm{hPa}$ related to its time-lag correction, whereas the GRUAN algorithm (primarily its calibration correction, which is not present in DigiCORA algorithms) produces mean RCs approaching $10 \%$ near $200 \mathrm{hPa}$.

Similar results are seen in the mean profiles at Manus (Fig. 4) except that actual RHs and RCs are slightly larger at the upper level (precipitation $p<200 \mathrm{hPa}$ ) than at Gan. The larger mean values of upper-level corrected $\mathrm{RH}$ at Manus ( $~ 40 \%-45 \%$ vs $25 \%-40 \%$ at Gan as seen in left-hand panels) are more typical of the deep moisture profiles and higher frequency of upper-level cloudiness found at sites within the Maritime Continent (Ciesielski et al. 2014). For the daytime Manus soundings, the RCs (middle-top panel) show that both algorithms result in similar corrections up to $200 \mathrm{hPa}$. Above this level, a maximum $\mathrm{RC}$ of $\sim 30 \%$ is seen for GRUAN and $\sim 40 \%$ for D3.64. As at Gan, the corrected Manus profiles show statistical consistency (right panels) at all levels.

At Nauru, where the GRUAN and D3.61N algorithms were applied, moisture conditions and correction characteristics are somewhat different. Lying near the eastern edge of the west Pacific warm pool, Nauru is considerably drier with lower RH, particularly above the boundary layer (Fig. 5) compared to the deep moisture profiles prevalent over the central Indian Ocean and Maritime Continent. For both daytime and nighttime Nauru soundings, differences in the RCs (middle panels) approach $10 \%$ for $T<0^{\circ} \mathrm{C}$. Since the D3.61N correction applied at this site is patterned after the GRUAN SRBC, corrections are nearly identical for $T \geq 0^{\circ} \mathrm{C}$ and gradually increase with altitude. However at colder temperatures, the larger GRUAN RCs are related to its calibration and time-lag corrections. These larger differences result in a consistency $k>1$ (right panels) indicating diminished statistical consistency and highlighting the limitations of the D3.61N algorithm at upper levels. If one considers only the daytime GRUAN corrections for the three sites in question, then it is worth noting that Nauru exhibits the largest RCs with values exceeding 30\% between 200 and 

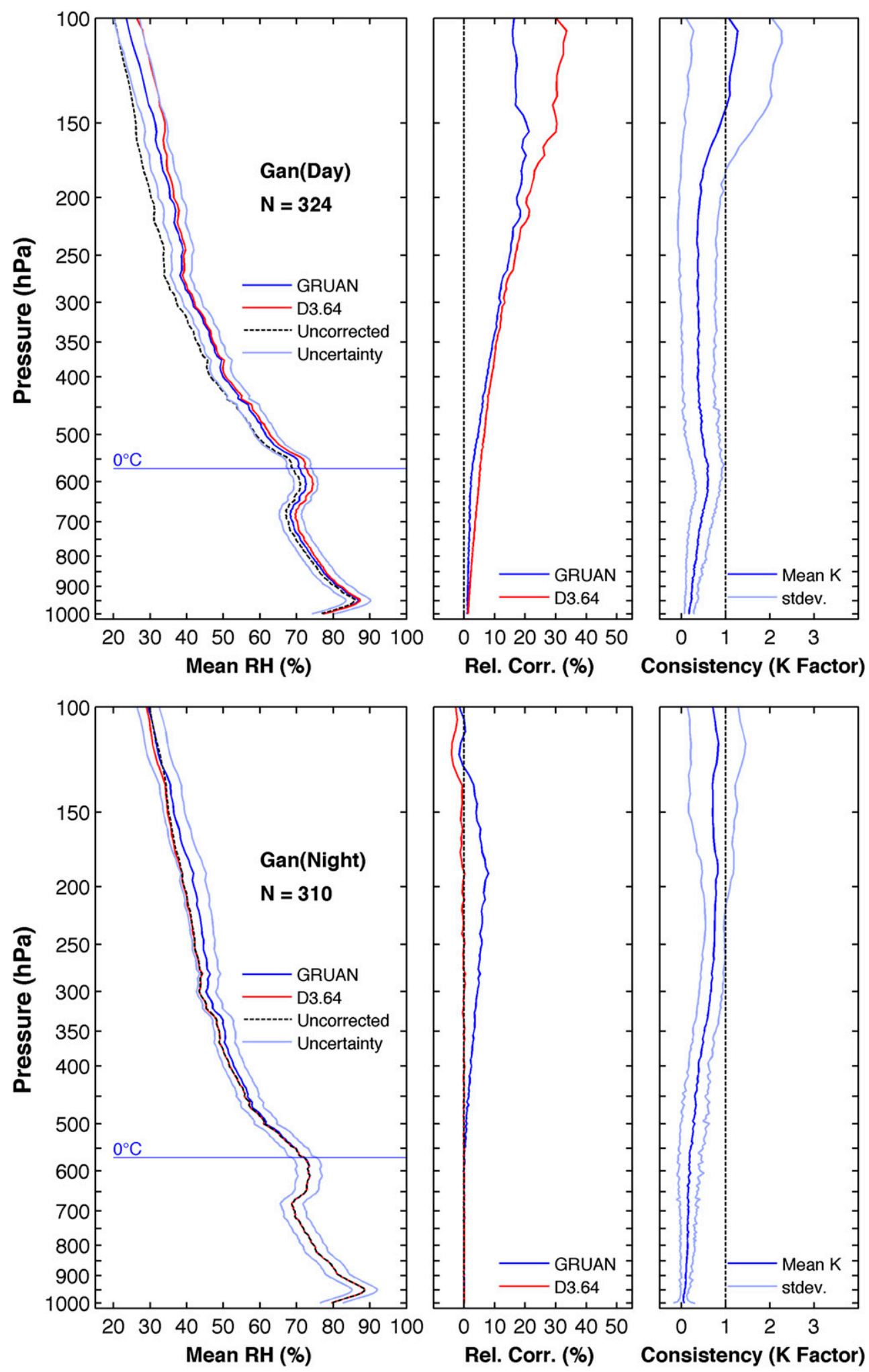

FIG. 3. Mean vertical profiles of RH at Gan for (top) daytime and (bottom) nighttime soundings for uncorrected and corrected data and uncertainty range for (left) GRUAN corrections, (middle) relative RH corrections, and (right) consistency of correction. Levels with $k \leq 1$ indicate good consistency between corrections. Freezing level and the number of sounding $(N)$ in each period are shown in (left). 

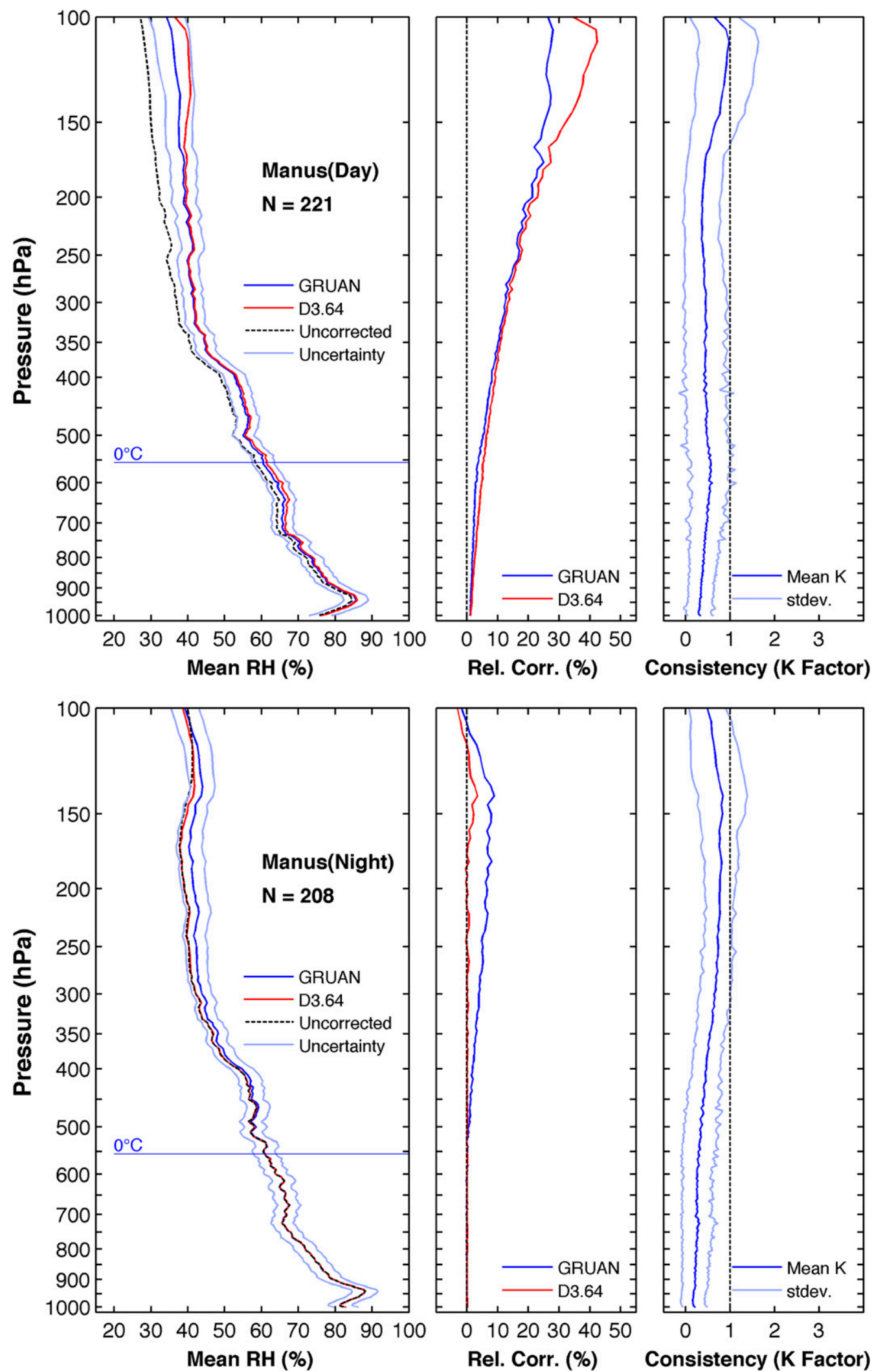

Rel. Corr. (\%)

Consistency (K Factor)
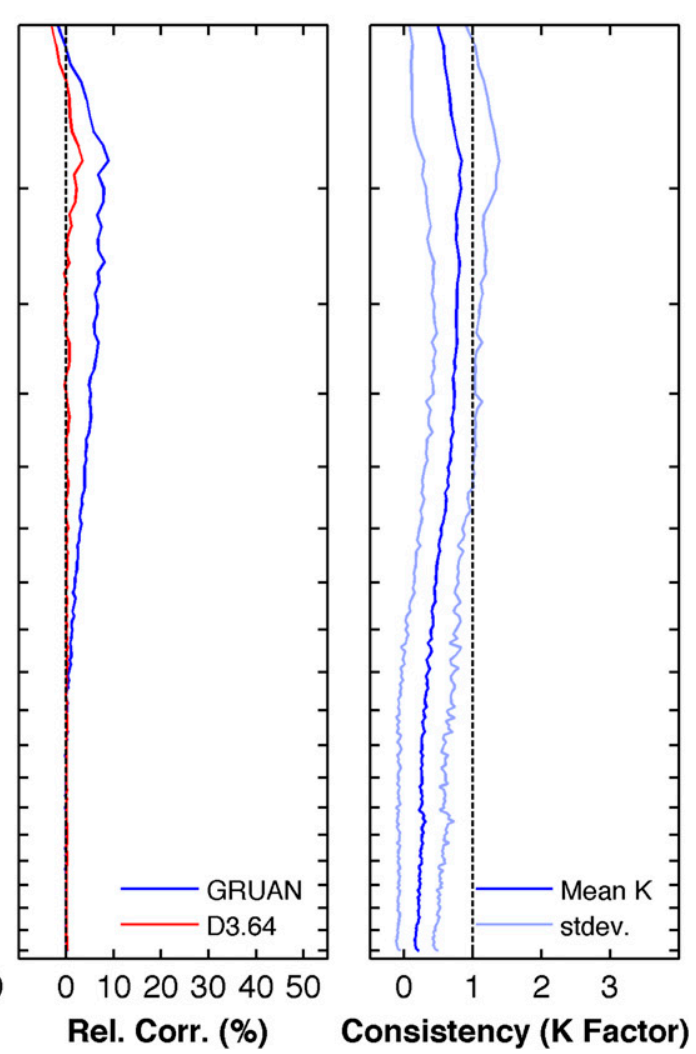

FIG. 4. As in Fig. 3, but for profiles at Manus. 

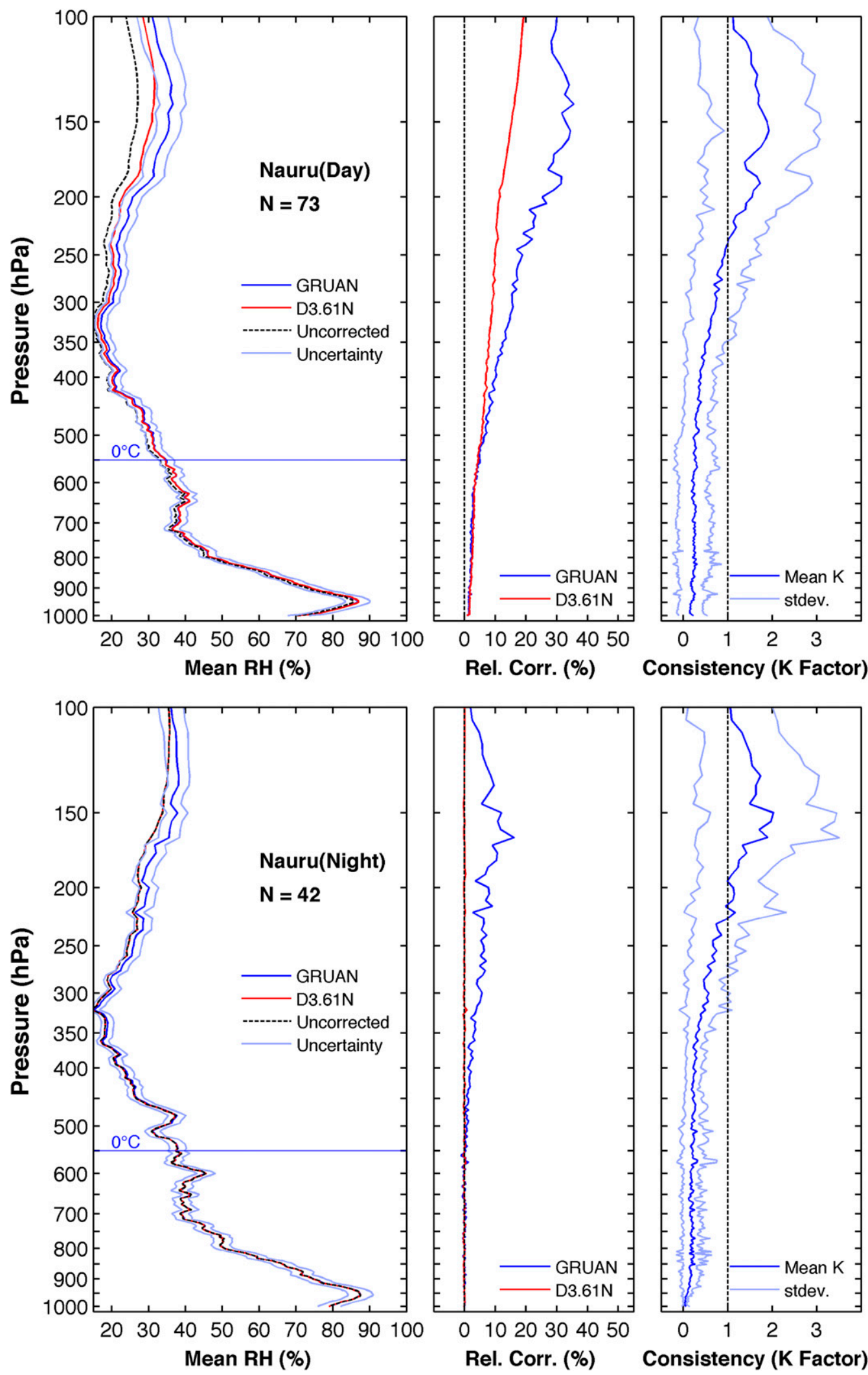

Rel. Corr. (\%)

Consistency (K Factor)

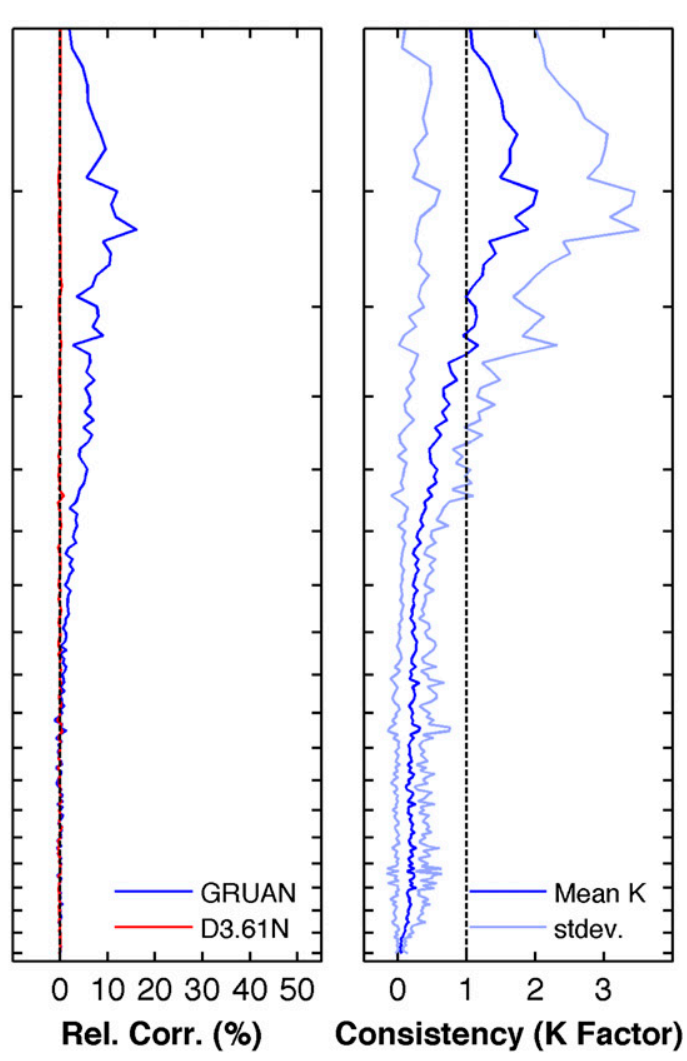

FIG. 5. As in Fig. 3, but for profiles at Nauru. 
$100 \mathrm{hPa}$ (middle panel). This is likely related to the fact that the daytime radiosondes at Nauru were all launched near local noon (see Table 2), when the SRBC is largest, whereas radiosonde launches at Manus and Gan were well distributed over the course of the daylight hours.

\section{Validation of corrections using independent data sources}

The most striking effect of the humidity corrections presented in Figs. 3-5 is the substantial increase in the daytime upper-level RH. Such an increase will impact the detection of saturated-layer frequency (SLF) in the sounding data (i.e., pressure levels with $\mathrm{RH}$ with respect to ice $\geqq 100 \%$ ). As seen in Fig. 6, the day (top panels) and night (bottom panels) increases in SLF are consistent with the RH corrections shown in Figs. 3-5 with larger SLF increases in D3.64-corrected sondes during the day and smaller increases at night. Considering both daytime and nighttime soundings, the SLFs more than double using corrected soundings with peak detection rates between 100 and $300 \mathrm{hPa}$ of $\sim 30 \%-40 \%$ at Gan and Manus and $\sim 15 \%-20 \%$ at Nauru using GRUAN-corrected soundings. These detection rates are largely consistent with CERES-estimated high-cloud $(p<300 \mathrm{hPa})$ coverage fractions of $34 \%, 39 \%$, and $15 \%$ for Gan, Manus, and Nauru, respectively (not shown), derived over the same period as the soundings. It is also worth noting that the higher SLFs at night shown in Fig. $6(\sim 5 \%$ higher for D3.64 and $\sim 20 \%$ higher for GRUAN) are generally consistent with the CERES analyses at these sites, which indicates an $\sim 8 \%$ increase in high-cloud coverage from day to night.

To further evaluate the corrections, TPWs from two sonde-independent data sources (i.e., GPS and MWR) are used. Figure 7 shows a comparison over the diurnal cycle for Gan between the uncorrected and corrected sonde estimates of TPW along with the GPS and MWR estimates. This analysis considers only the times when all estimates are available with the number of comparison observations in each period shown along the bottom of the top panel. Also shown here is the uncertainty range of TPW based on the uncertainty of GRUAN RH measurements. To calculate the uncertainty range of $\mathrm{TPW}$, the mean vertical profiles of RH uncertainty range were converted to mixing ratio and then integrated through the entire column.

This analysis clearly shows the impact of the daytime corrections, primarily the SRBC, on increasing TPW. Differences between the uncorrected sonde values and MWR TPW are $\sim 2.0 \mathrm{~mm}$ near local noon but decrease to less than $1 \mathrm{~mm}$ with corrected data. Similar agreement between the corrected sonde TPW and MWR are seen over the diurnal cycle at Manus (Fig. 8). At all three sites (comparison at Nauru not shown ${ }^{3}$ ), the corrected sonde TPWs are slightly drier than the MWR values during the daylight hours and slightly moister than the MWR at night. While daytime TPW differences between sondes and MWR are somewhat smaller for D3.64 than GRUAN, in all cases the differences are well within the uncertainty of the GRUAN estimates. We also note that while both the uncorrected and corrected sondes have higher TPWs than the MWR at night, in fact the nighttime corrections, particularly the larger upper-level GRUAN moistening (bottom panels in Figs. 3 and 4), have little if any impact on TPW, since moisture in levels above $500 \mathrm{hPa}$ contributes roughly only $5 \%$ to TPW.

Table 3 indicates the differences in overall TPW means (sonde-corrected minus MWR) range from -0.7 to $+0.1 \mathrm{~mm}$ for the daytime values and +0.3 to $+0.9 \mathrm{~mm}$ for nighttime values, consistent with the diurnal cycle plots (Figs. 7 and 8). These differences represent $<2 \%$ of the mean TPW values. Observing similar small sonde biases relative to MWR estimates at several DYNAMO sites, Ciesielski et al. (2014) noted that these differences were within the stated accuracy of the MWR and radiosonde measurements and not statistically significant to warrant additional sonde corrections. It is also noteworthy upon closer inspection of Fig. 1 that the NCEP reanalysis of mean TPW at Gan is considerably lower than the sonde-corrected and MWR estimates shown in Table 3 (e.g., $\geq 53 \mathrm{~mm}$ for GRUAN vs $48.3 \mathrm{~mm}$ for NCEP). This model TPW low bias was also noted in Ciesielski et al. (2014, their Fig. 20) and is the result of a low-level dry bias in the models in the Indian Ocean region (Nagarajan and Aiyyer 2004).

For reasons unclear at this time, the GPS TPW values at all three sites are systematically $1.5-2.0 \mathrm{~mm}$ lower than other estimates. While within the uncertainty of the GRUAN estimates, Ciesielski et al. (2014) showed that the GPS TPW biases are indeed statistically significant. In addition, they examined collocated GPS and corrected sonde data at 11 sites in DYNAMO and found GPS dry biases ranging from -0.2 to $-2.7 \mathrm{~mm}$. While the source of this bias is unclear, it is consistent with the results reported by Thomas et al. (2011) that current state-of-the-art GPS analysis techniques underestimate TPW by $\sim 1.8 \mathrm{~mm}$ in high latitude and dry atmospheric conditions. Despite the GPS dry bias, all estimates of TPW in Figs. 7 and 8 exhibit slight but similar diurnal variability. In particular, note the TPW increase from 1700 to 2000 local time (LT) at Gan and the TPW dip at 0100 LT at Manus.

\footnotetext{
${ }^{3}$ The diurnal cycle of TPW at Nauru is not shown here because it had sonde observations only twice daily.
} 
Frequency of Saturated Layers (\%) by Day
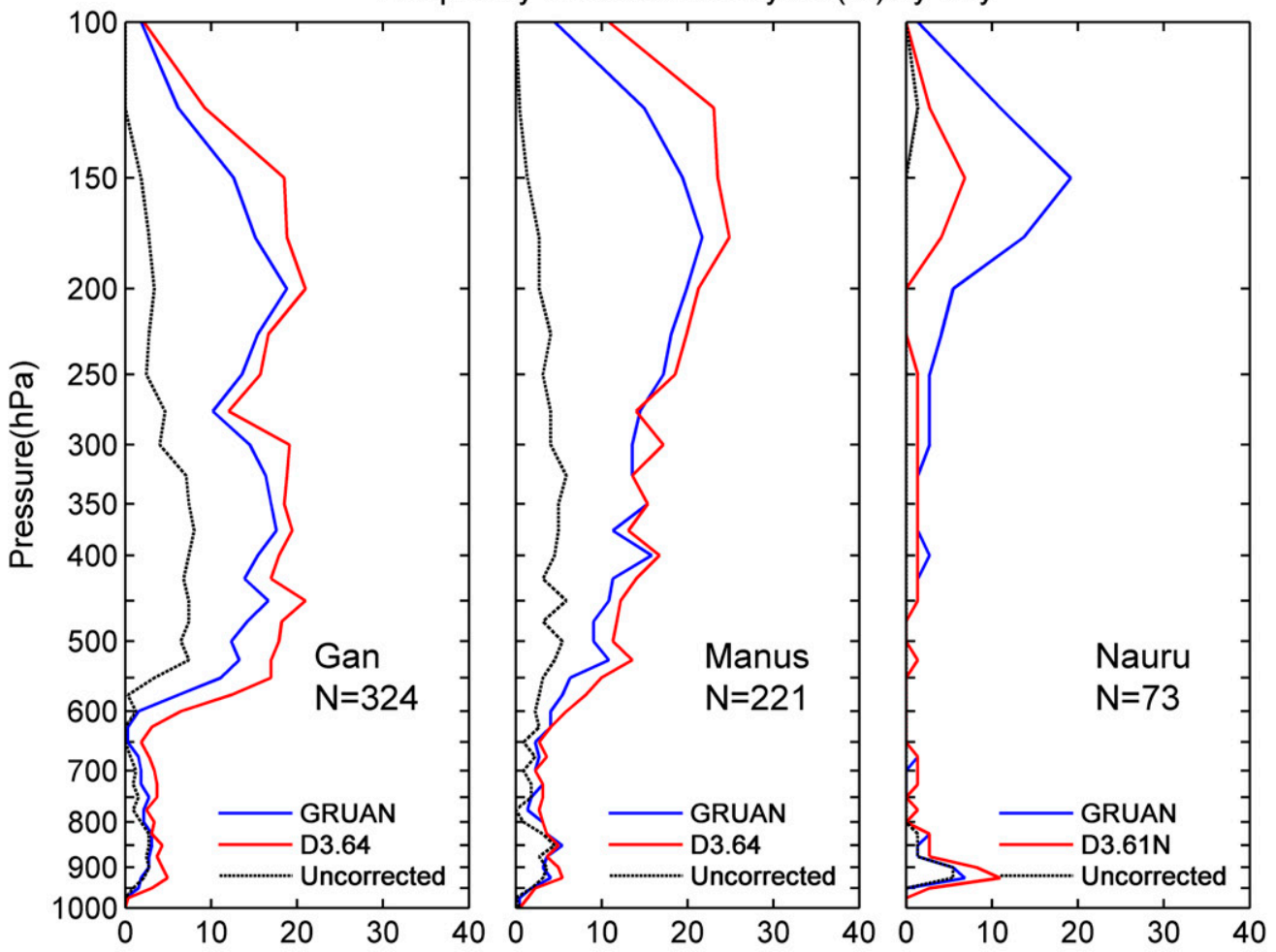

Frequency of Saturated Layers (\%) by Night
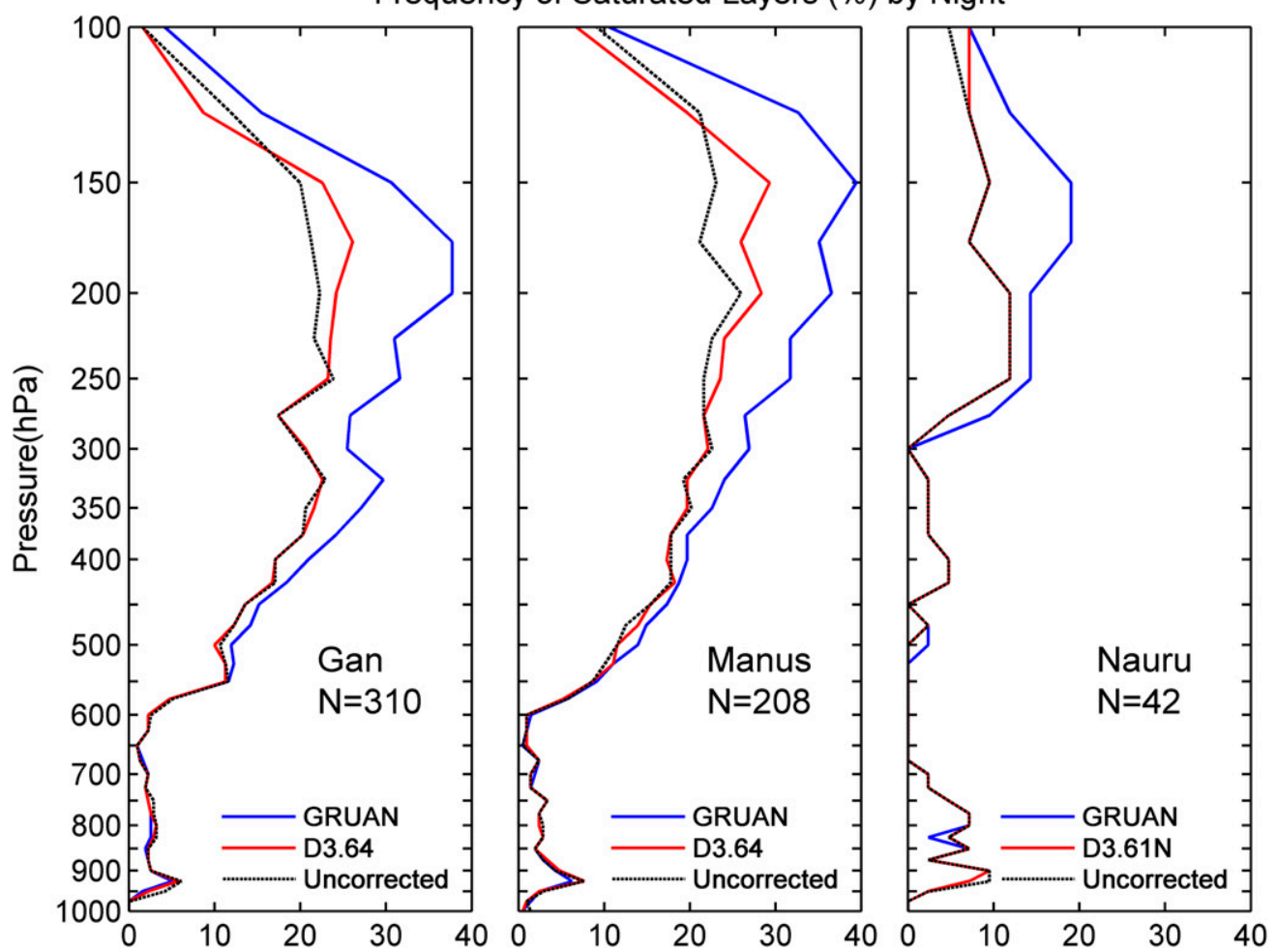

FIG. 6. Frequency of saturated layers (RH w.r.t. ice $\geq 100 \%$ ) using uncorrected (dashed), DigiCORAcorrected (red) and GRUAN-corrected (blue) (top) daytime and (bottom) nighttime soundings for (left) Gan, (middle) Manus, and Nauru (right). Note: the results at Gan and Manus are based on the D3.64 correction algorithm, while those at Nauru are based on the D3.61N correction. 

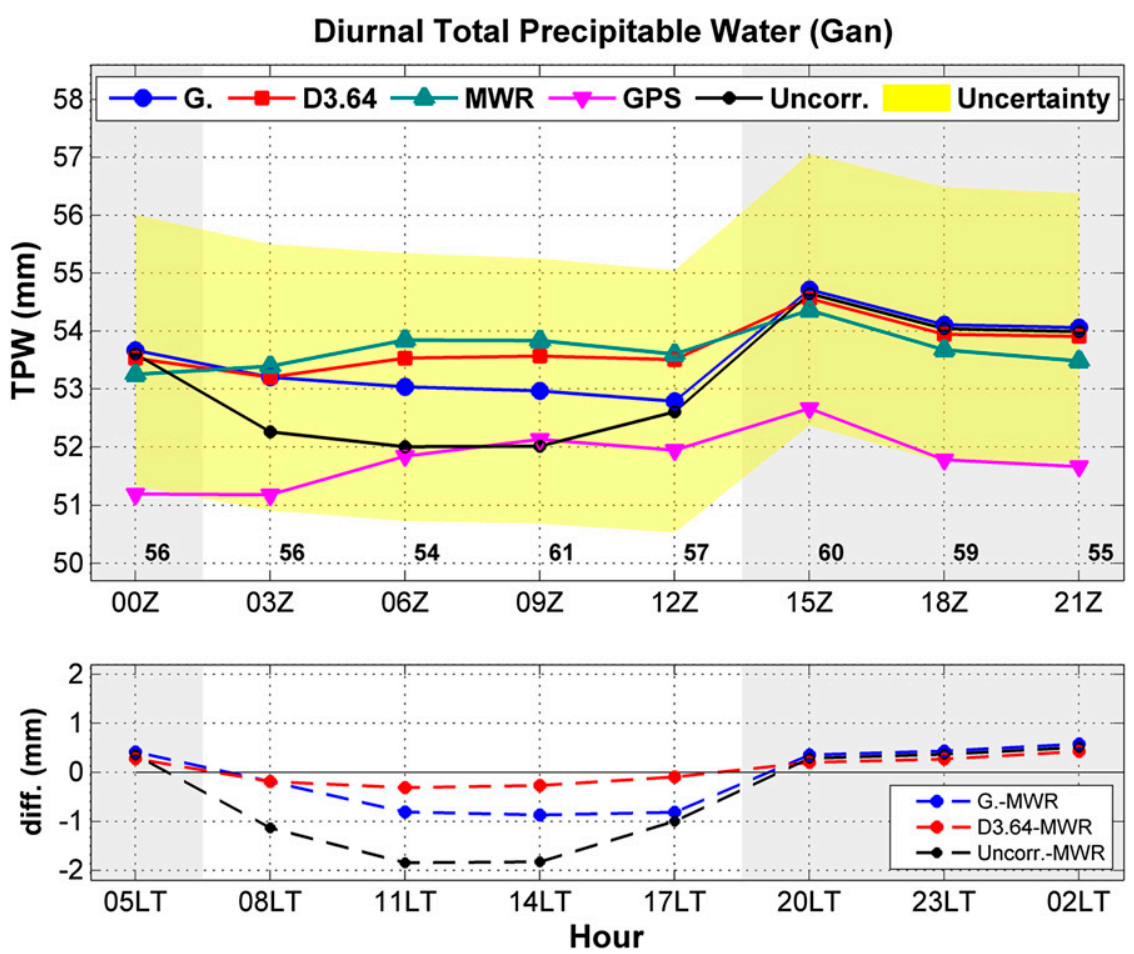

FIG. 7. (top) Mean diurnal cycle of TPW (mm) for Gan with uncorrected sounding data (black line), GRUAN-corrected data (blue line), DigiCORA-corrected data (red line), MWR (green line), and GPS (magenta line). Light yellow shading indicates TPW uncertainty based on GRUAN estimates. Gray shading indicates nighttime hours. (bottom) TPW difference $(\mathrm{mm})$ between uncorrected and corrected soundings and MWR. Note that the time axis is (top) UTC time and (bottom) local time.

We perform regression analysis of GPS and MWR TPW to better characterize the nature of the GPS dry bias (Fig. 9). Here rain-contaminated MWR estimates, indicated with red pluses, are excluded in the analysis. While the GPS dry bias is present over the full range of TPW values at all sites, the smaller-than-one regression slopes indicate that the dry bias increases as the column moisture increases. Similar results were also observed from the ARM Central Facility site at Lamont, Oklahoma, in the recent Midlatitude Continental Convective Clouds Experiment (Petersen and Jensen 2012). In summary, the issues of the GPS dry bias and the increase of this bias in moister environments are not limited to the tropics.

\section{Summary and concluding remarks}

This study uses sounding data from DYNAMO, a recent international field campaign centered over the Indian Ocean, to examine humidity corrections of Vaisala RS92 radiosondes in a tropical oceanic environment. Specifically, GRUAN-corrected Vaisala RS92 soundings are compared with corrections produced with DigiCORA ground station software at three DYNAMO sonde sites (Gan, Manus, and Nauru) that span a broad range of moisture conditions.
Two DigiCORA algorithms are examined: D3.64 used at Gan and Manus, and D3.61N used at Nauru. The uncertainty estimates of the GRUAN data product are used to examine the statistical consistency of the various corrections.

At the Gan and Manus sites, mean vertical profiles of RH show only small differences (on the order of a few percent at any given level) between the D3.64 and GRUAN corrections such that the corrections are considered statistically consistent at most levels. One reason for the correction differences is that GRUAN applies a small calibration RH correction of $0 \%-3 \%$ (at $T<0^{\circ} \mathrm{C}$ ) that is not present in the D3.64 correction algorithm. Beyond this, the proprietary nature of the D3.64 correction limits a more complete explanation for these differences. In general, these corrections produce an RH increase that increases with altitude. For example, in daytime soundings the relative $\mathrm{RH}$ correction increases from a few percent at $T>0^{\circ} \mathrm{C}$ to a maximum of $20 \%-$ $40 \%$ between 100 and $200 \mathrm{hPa}$. While D3.64 produces slightly larger $\mathrm{RH}$ increases in the daytime sondes, GRUAN shows larger increases at night. In contrast at Nauru, the GRUAN algorithm produces larger RH increases both day and night for $T<0^{\circ} \mathrm{C}$ than the D3.61N 

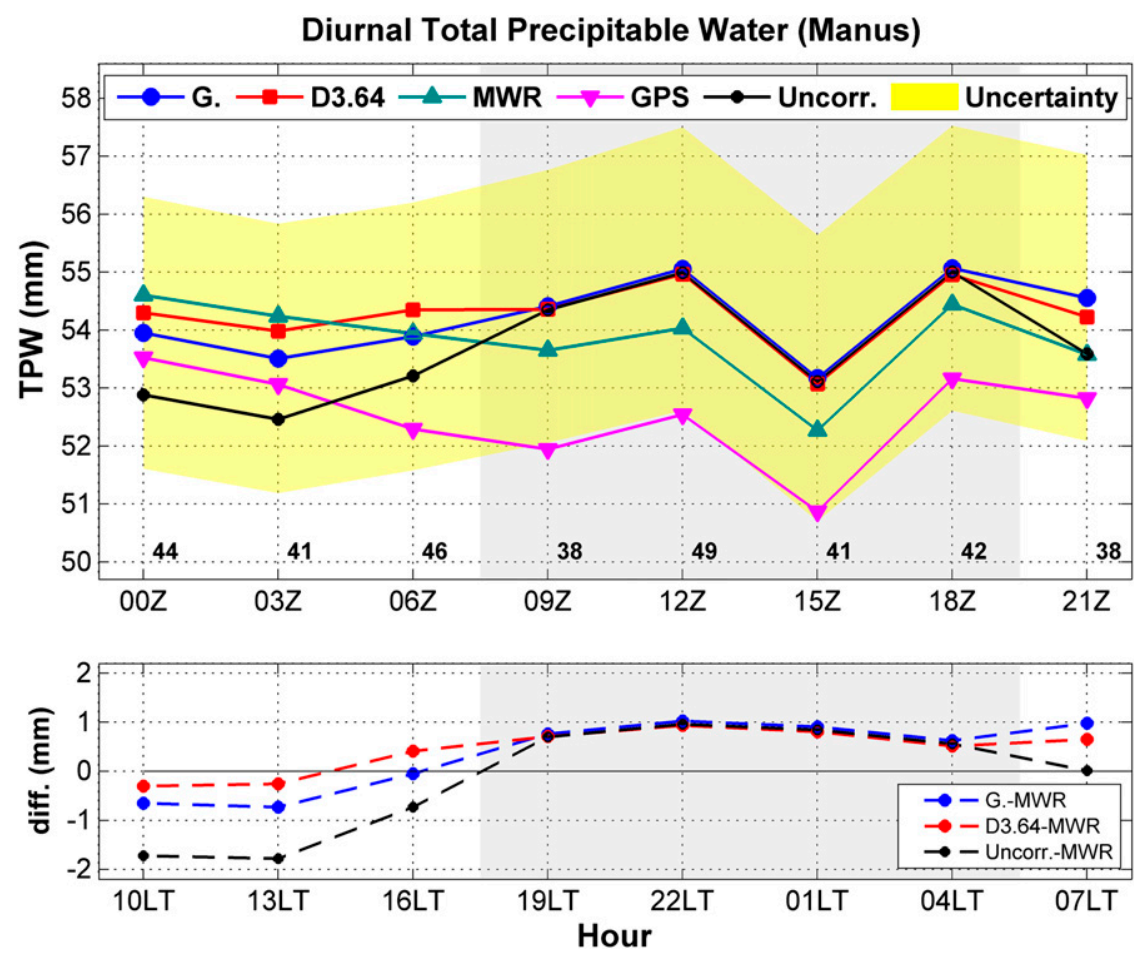

FIG. 8. As in Fig. 7, but for Manus.

corrections. The lack of consistency between the corrections at $p<200 \mathrm{hPa}$ at Nauru emphasizes the limitations of the D3.61N algorithm at these higher levels. The implications of these corrections on the climate record are likely small in the lower atmosphere but potentially significant in the upper troposphere/lower stratosphere, where the frequency of detected saturated layers more than doubles using corrected soundings and the role of water vapor in climate change is strongly debated (Luo et al. 2007). Using D3.64- and GRUANcorrected soundings, the detected saturated layer rates are largely consistent with CERES-estimated highcloud coverage fractions.

In evaluating corrected humidity sonde data, excellent agreement was found at all sites between radiosonde and MWR values of TPW. Relative to the MWR estimates, all sounding corrections show a small $(<2 \%)$ daytime dry bias and a similarly small nighttime moist bias. These differences are well within the uncertainties provided as part of the GRUAN data and suggest that the correction algorithms examined herein perform well over a wide range of tropical moisture conditions. On the other hand, GPS TPW shows a systematic dry bias relative to the corrected sonde and MWR estimates of $\sim 5 \%$ (or about $2 \mathrm{~mm}$ ). Scatterplots of GPS and MWR TPW indicate that the GPS dry bias increases as the column moisture content increases. While beyond the scope of this study, understanding the causes for this dry bias is important because of the wide use of GPS TPW data in many weather and climate applications.

Since operational radiosonde data, as well as operational MWR and GPS data used in this study, do not provide any uncertainty estimates, it is possible that the uncertainties of MWR and of GPS data are sufficiently large to explain the differences between the TPW measurements. These differences represent our current

TABLE 3. Daytime and nighttime mean TPW (mm) from upper-air soundings and from independent estimates of MWR and GPS. The TPW uncertainty is computed from the GRUAN estimate of RH uncertainty.

\begin{tabular}{|c|c|c|c|c|}
\hline Station & GRUAN TPW and uncertainty & DigiCORA TPW & MWR TPW & GPS TPW \\
\hline Gan day & $53.0 \pm 2.3$ & 53.5 & 53.7 & 51.8 \\
\hline Gan night & $54.1 \pm 2.3$ & 54.0 & 53.7 & 51.8 \\
\hline Manus day & $54.0 \pm 2.4$ & 54.2 & 54.1 & 53.0 \\
\hline Manus night & $54.4 \pm 2.4$ & 54.3 & 53.6 & 52.1 \\
\hline Nauru day & $40.4 \pm 1.9$ & 40.4 & 40.7 & 38.2 \\
\hline Nauru night & $41.3 \pm 1.9$ & 41.3 & 40.4 & 38.7 \\
\hline
\end{tabular}



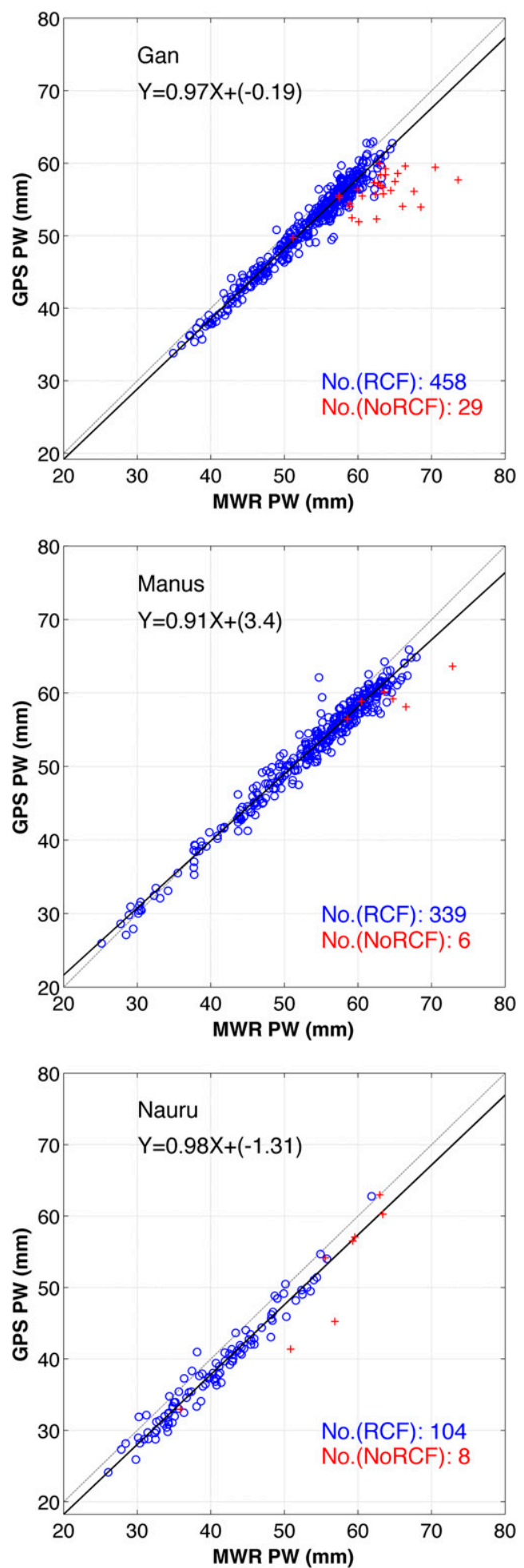

FIG. 9. Scatter diagram of TPW (mm) with GPS TPW plotted along $y$ axis and MWR TPW plotted along $x$ axis, at (top) Gan, (middle) Manus, and (bottom) Nauru. Gray dashed line is 1-1 line, blue dots are those values that passed the rain contaminant filter test and red pluses are those that did not. The black thick line indicates the least squares fit to TPW without rain-contaminated cases. level of understanding of the accuracy of TPW. To improve our ability to measure TPW requires that the uncertainties of TPW measurements by MWR, as well as by GPS, be provided under the conditions of the respective instruments. Identifying the leading terms of uncertainty should help us determine ways to improve these observations.

The uncertainty provided as part of the GRUAN data is based on the current understanding of these measurements (see Dirksen et al. 2014). Improvements in estimation of these uncertainties may include a better characterization of the radiation dry bias and of the time response coefficients of the humidity sensor. While additional independent datasets with uncertainties less than those of the GRUAN-processed data may help identify improvements in the GRUAN data, few such datasets are currently available.

In conclusion, it is encouraging that sonde manufacturers are continuing to improve humidity measurements by enhancements to sonde hardware and better software algorithms. However, if we are to achieve radiosonde datasets useful for climate study purposes, it is essential that these corrections and algorithms be well documented and readily available, as emphasized in Wang et al. (2013). Last but not least, as discussed in the appendix, understanding subtle differences in correction schemes is contingent on complete and accurate metadata for each scheme.

Acknowledgments. The authors thank Richard Johnson for his many insightful suggestions regarding the details of the analyses in this paper. We thank ECMWF for making available its operational analyses and DOE ARM for allowing us to use data (soundings, MWR and GPS retrievals of TPW) from three of its ARM-equipped tropical sites. We also acknowledge the helpful suggestions of three anonymous reviewers. This research was supported by National Taiwan University under Grant NTU-CESRP-104R7604-1, the Ministry of Science and Technology in Taiwan under Grants MOST 103-2625-M002-003 and MOST 103-2111-M-002-010, the National Science Foundation under Grants AGS-1059899 and AGS-1360237, and NASA Grant NNX13AF74G.

\section{APPENDIX}

\section{Importance of Accurate and Complete Metadata}

Appropriate use of radiosonde data, or any other dataset for that matter, requires detailed information about the processing software and the instrument that was used. Until 2011 all versions of the Vaisala DigiCORA processing 
software applied a correction to the humidity measurements based only on the ground check and applied a smoothing filter. The first version that included a correction for both radiation dry bias and sensor time lag is DigiCORA, version 3.64. However, knowing the software version is not sufficient to describe the corrections, since this software version allows disabling these additional corrections. Data obtained through the Global Telecommunication System (GTS) in FM35 format does not provide any information about whether the data have been corrected. Data obtained in WMO Binary Universal Form for Representation of Meteorological Data (BUFR) format may contain the software version, but software versions 3.64 and 3.65 do not contain information as to whether these corrections have been used. Only starting with software version 3.66 has it been possible to provide BUFR information describing whether corrections have been applied. Therefore, users of current Vaisala radiosonde data should pay close attention to the metadata provided with the data. When metadata are insufficient, it may not be possible to know whether these corrections have been applied.

In addition to the software version, users need also to pay attention to the ground check correction applied in the processing. The ground check correction for relative humidity depends on the condition of the desiccant, which in particular at tropical sites may not be as good as it should be. The GRUAN processing (Dirksen et al. 2014) removes the ground check correction for all soundings and thus avoids degrading the humidity profile as a result of poor desiccant.

Although WMO requires all operational radiosonde sites to provide data in BUFR format using all available metadata fields, this practice has not yet been implemented at a significant number of stations. The new corrections implemented by Vaisala are only one example of the importance of accurate metadata, such that all suppliers and users of metadata should carefully consider the accuracy of the metadata provided.

\section{REFERENCES}

Bock, O., and M. Nuret, 2009: Verification of NWP model analyses and radiosonde humidity data with GPS precipitable water vapor estimates during AMMA. Wea. Forecasting, 24, 10851101, doi:10.1175/2009WAF2222239.1.

—, F. Guichard, S. Janicot, J. P. Lafore, M. N. Bouin, and B. Sultan, 2007: Multiscale analysis of precipitable water vapor over Africa from GPS data and ECMWF analyses. Geophys. Res. Lett., 34, L09705, doi:10.1029/2006GL028039.

Cadeddu, M. P., J. C. Liljegren, and D. D. Turner, 2013: The Atmospheric Radiation Measurement (ARM) program network of microwave radiometers: Instrumentation, data, and retrievals. Atmos. Meas. Tech., 6, 2359-2372, doi:10.5194/ amt-6-2359-2013.
Cady-Pereira, K. E., M. W. Shephard, D. D. Turner, E. J. Mlawer, S. A. Clough, and T. J. Wagner, 2008: Improved daytime column-integrated precipitable water vapor from Vaisala radiosonde humidity sensors. J. Atmos. Oceanic Technol., 25, 873-883, doi:10.1175/2007JTECHA1027.1.

Ciesielski, P. E., and Coauthors, 2014: Quality-controlled upper-air sounding dataset for DYNAMO/CINDY/AMIE: Development and corrections. J. Atmos. Oceanic Technol., 31, 741-764, doi:10.1175/JTECH-D-13-00165.1.

Dai, A., J. Wang, P. W. Thorne, D. E. Parker, L. Haimberger, and X. L. Wang, 2011: A new approach to homogenize daily radiosonde humidity data. J. Climate, 24, 965-991, doi:10.1175/ 2010JCLI3816.1.

Dirksen, R. J., M. Sommer, F. J. Immler, D. F. Hurst, R. Kivi, and H. Vömel, 2014: Reference quality upper-air measurements: GRUAN data processing for the Vaisala RS92 radiosonde. Atmos. Meas. Tech. Discuss., 7, 3727-3800, doi:10.5194/ amtd-7-3727-2014.

Immler, F. J., and M. Sommer, 2011: Brief description of the RS92 GRUAN data product (RS92-GDP). Revision 1.1, GRUAN Tech. Doc. GRUAN-TD-4, 17 pp. [Available online at http:// www.dwd.de/bvbw/generator/DWDWWW/Content/Projekte/ Gruan/Downloads/documents/gruan-td-4,templateId=raw, property $=$ publicationFile.pdf $/$ gruan-td-4.pdf.]

_ J. Dykema, T. Gardiner, D. N. Whiteman, P. W. Thorne, and H. Vömel, 2010: A guide for upper-air reference measurements: Guidance for developing GRUAN data products. Atmos. Meas. Tech., 3, 1217-1231, doi:10.5194/amt-3-1217-2010.

Liou, Y., Y. Teng, T. V. Hove, and J. C. Liljegren, 2001: Comparison of precipitable water observations in the near tropics by GPS, microwave radiometer, and radiosondes. J. Appl. Meteor., 40, 5-15, doi:10.1175/1520-0450(2001)040<0005: COPWOI $>2.0 . \mathrm{CO} ; 2$.

Luo, Z., D. Kley, R. H. Johnson, and H. Smit, 2007: Ten years of measurements of tropical upper-tropospheric water vapor by MOZAIC. Part I: Climatology, variability, transport, and relation to deep convection. J. Climate, 20, 418-435, doi:10.1175/ JCLI3997.1.

Miloshevich, L. M., H. Vömel, D. N. Whitman, and T. Leblanc, 2009: Accuracy assessment and correction of Vaisala RS92 radiosonde water vapor measurements. J. Geophys. Res., 114, D11305, doi:10.1029/2008JD011565.

Nagarajan, B., and A. Aiyyer, 2004: Performance of the ECMWF operational analyses over the tropical Indian Ocean. Mon. Wea. Rev., 132, 2275-2282, doi:10.1175/ 1520-0493(2004)132<2275:POTEOA > 2.0.CO;2.

Nash, J., T. Oakley, H. Vömel, and W. Li, 2011: WMO intercomparisons of high quality radiosonde systems. WMO Tech. Doc. WMO/TD-1580, Instruments and Observing Methods Rep. 107, 238 pp. [Available online at http://www.wmo.int/pages/prog/ www/IMOP/publications/IOM-107_Yangjiang.pdf].

Petersen, W. A., and M. Jensen, 2012: The NASA-GPM and DOEARM Midlatitude Continental Convective Clouds Experiment (MC3E). The Earth Observer, No. 24, Earth Observing System Project Science Office, Greenbelt, MD, 12-18. [Available online at http://pmm.nasa.gov/sites/default/files/document_files/ Earth_Observer_Jan_2012_MC3E.pdf.]

Seidel, D. J., and Coauthors, 2009: Reference upper-air observations for climate: Rationale, progress, and plans. Bull. Amer. Meteor. Soc., 90, 361-369, doi:10.1175/2008BAMS2540.1.

Thomas, I. D., M. A. King, P. J. Clarke, and N. T. Penna, 2011: Precipitable water vapor estimates from homogeneously reprocessed 
GPS data: An intertechnique comparison in Antarctica. J. Geophys. Res., 116, D04107, doi:10.1029/2010JD013889.

Thorne, P. W., J. R. Lanzante, T. C. Peterson, D. J. Seidel, and K. P. Shine, 2011: Tropospheric temperature trends: History of an ongoing controversy. Wiley Interdiscip. Rev.: Climate Change, 2, 66-88, doi:10.1002/wcc.80.

Vaisala, cited 2015: Sounding data continuity. [Available online at http:// www.vaisala.com/en/products/soundingsystemsandradiosondes/ soundingdatacontinuity/Pages/default.aspx.]

Vömel, H., D. E. David, and K. Smith, 2007a: Accuracy of tropospheric and stratospheric water vapor measurements by the cryogenic frost point hygrometer: Instrumental details and observations. J. Geophys. Res., 112, D08305, doi:10.1029/2006JD007224.

— RS92 humidity sensor. J. Atmos. Oceanic Technol., 24, 953 963, doi:10.1175/JTECH2019.1.

Wang, J., L. Zhang, A. Dai, T. Van Hove, and J. Van Baelen, 2007: A near-global, 2-hourly data set of atmospheric precipitable water from ground-based GPS measurements. J. Geophys. Res., 112, D11107, doi:10.1029/2006JD007529.
,,,--- F. Immler, M. Sommer, and H. Vömel, 2013: Radiation dry bias correction of Vaisala RS92 humidity data and its impact on historical radiosonde data. J. Atmos. Oceanic Technol., 30, 197-214, doi:10.1175/JTECH-D-12-00113.1.

Ware, R. H., and Coauthors, 2000: SuomiNet: A real-time national GPS network for atmospheric research and education. Bull. Amer. Meteor. Soc., 81, 677-694, doi:10.1175/ 1520-0477(2000)081<0677:SARNGN > 2.3.CO;2.

Wielicki, B. A., B. R. Barkstrom, E. F. Harrison, R. B. Lee III, G. L. Smith, and J. E. Cooper, 1996: Clouds and the Earth's Radiant Energy System (CERES): An Earth Observing System experiment. Bull. Amer. Meteor. Soc., 77, 853-868, doi:10.1175/ 1520-0477(1996)077<0853:CATERE $>2.0$. CO;2.

Yoneyama, K., M. Fujita, N. Sato, M. Fujiwara, Y. Inai, and F. Hasebe, 2008: Correction for radiation dry bias found in RS92 radiosonde data during the MISMO field experiment. SOLA, 4, 13-16, doi:10.2151/sola.2008-004.

C. Zhang, and C. N. Long, 2013: Tracking pulses of the Madden-Julian Oscillation. Bull. Amer. Meteor. Soc., 94, 1871-1891, doi:10.1175/BAMS-D-12-00157.1. 